\title{
Liability-Driven Investing for Life Insurers
}

\author{
David van Bragt and Dirk-Jan Kort \\ Insurance Risk Managament, ORTEC Finance, Max Euwelaan 78, Rotterdam, 3062 MA, Netherlands.
}

Liability-driven investing (LDI) has recently emerged as a powerful paradigm in financial risk management. The basic idea behind LDI is to split the company's balance sheet into two separate balance sheets: one for the liabilities and the matching assets and one for the other (return) assets and the surplus. We show that constructing a proper liability-hedging portfolio (LHP) is very attractive for life insurers because the liability-driven risks can be suppressed without a negative impact on overall return. When these risks are covered by the LHP, the return assets can be optimised using well-known (Markowitz) optimisation techniques or (equity) hedge strategies. The LDI approach thus stimulates insurers to address all risks embedded in the insurance liabilities and facilitates the subsequent optimisation of the return assets.

The Geneva Papers (2011) 36, 30-49. doi:10.1057/gpp.2010.36;

published online 1 December 2010

Keywords: liability-driven investing; portfolio construction; life insurers; pension funds; embedded options

\section{Introduction}

Liability-driven investing (LDI) is characterised by a central role of the liabilities in the asset allocation process. LDI solutions have been proposed by investment banks and asset managers after many financial institutions were severely hit by falling interest rates and dropping stock prices in the 2001-2003 and 2008-2009 periods. ${ }^{1}$ As a consequence of the huge impact of market conditions on key financial institutions, regulating authorities have also tightened the solvency requirements and accounting standards. The following elements are crucial in this regulatory reform:

- Total balance sheet approach (i.e., assets and liabilities);

- economic or market value;

- Value-at-Risk or Conditional Value-at-Risk (CVaR) approach to determine the required capital;

- wide range of risks (market, insurance, operational, ...);

- capital requirements based on a confidence level on a one year basis; and,

- standard vs. internal models.

Using these elements, several countries have developed their own solvency tests. Such tests typically use pre-described stress scenarios for the different risk factors

\footnotetext{
${ }^{1}$ Maton (2007) and PIMCO (2007) provide an informal discussion of the factors driving institutions towards LDI.
} 
(e.g. a shock of -40 per cent for stocks and a shift up and down of the interest rate curve). Institutions should demonstrate that their surplus is sufficiently large to adsorb these shocks and prevent the occurrence of a negative surplus. The combined effect of the different shocks is determined using assumptions about the correlations between the different risk factors. Large institutions are also encouraged to develop their own internal models to determine the required capital.

The Netherlands has been a frontrunner in these developments by adopting the FTK solvency testing framework, which focuses on overall balance sheet risks (including all assets and liabilities). ${ }^{2}$ Twin Peaks and Individual Capital Assessment in the United Kingdom, Swiss Solvency Test in Switzerland and the Traffic Light System in Sweden are examples of similar developments in other countries. The upcoming European Solvency II guidelines for insurers, expected to be in place in 2013, will incorporate these local frameworks. ${ }^{3}$ Anticipating these new requirements, financial institutions in many European countries have now moved towards LDI solutions. The idea behind these solutions is that the required capital is reduced by properly matching the liabilities, which makes the company less vulnerable in case of adverse economic situations. Van Bragt et al. ${ }^{4}$ for example showed that the available capital for life insurers may decrease significantly under Solvency II because the market value of "embedded" options in insurance contracts (like profit-sharing mechanisms or minimum return guarantees) needs to be considered explicitly. This stresses the need to properly hedge the (potentially very high) costs of these embedded options.

The academic literature with respect to the application of LDI is still rather small. Amenc et $a .^{5}$ apply the LDI concept to insurance companies and private wealth management. They argue that the LDI concept can be applied successfully in this case and give examples of the effectiveness of both static and dynamic LDI strategies. They show that, given a surplus optimisation perspective, more efficient asset mixes can be found by introducing a liability-hedging portfolio (LHP) in the menu of asset classes. LDI solutions thus consist of three basic building blocks (cash, LHP and a performance portfolio), as opposed to the allocation to standard asset classes as in the context of regular surplus optimisation techniques.

Mindlin ${ }^{6}$ discusses the relevance of LDI solutions for pension funds. He argues that the LDI concept is inadequate for open-ended pension plans since matching assets for ongoing plans rarely exist. For example, if the matching asset for an ongoing plan existed, it would contain bonds indexed to wage inflation with maturities of 50 years or more. Mindlin therefore concludes that the LDI approach is more appropriate for

\footnotetext{
2 In Dutch, FTK stands for "Financieel ToetsingsKader" (Financial Assessment Framework).

${ }^{3}$ Similar to Basel II, Solvency II consists of three different pillars. Pillar I concerns the measurement of assets, liabilities and the required capital. This pillar thus focuses on the more quantitative regulatory aspects. Pillar II concerns the supervisory review process and therefore focuses on the more qualitative aspects. Pillar III addresses disclosure requirements: transparency, open information, etc. See the introductory guide to Solvency II by Towers Perrin (2006) for more information. Amenc et al. (2006) explore the effects of Solvency II and IFRS on ALM and asset management in the insurance industry.

${ }^{4}$ Van Bragt et al. (2010).

5 Amenc et al. (2006, 2007).

${ }^{6}$ Mindlin (2006).
} 
terminated plans or plans for which termination is likely. He also stresses that the impact of other risk factors (contribution risk, solvency risk, accounting risk, etc.) is not weighted appropriately by LDI proponents.

Boender $^{7}$ is also critical of a straightforward application of LDI techniques for pension funds. He points out that LDI is not a completely new concept at all: asset and liability management (ALM) for pension funds has given liabilities a central role a long time ago. See for example Zenios and $\mathrm{Ziemba}^{8}$ or Ziemba and Mulvey ${ }^{9}$ for excellent and broad overviews. Chapter 18 (by Boender et al.) and Chapter 20 (by Dondi et al.) in Zenios and $\mathrm{Ziemba}^{8}$ are particularly relevant chapters in these volumes.

Boender $^{7}$ also demonstrates, with a practical example, that most LDI solutions for open-ended pension funds lead to solutions that are too risk-averse and, as a consequence, too expensive. He remarks that it is common practice that, given an agreed-upon asset allocation, sponsors contribute more in case of a decreasing funded ratio. This risk-reducing effect (for the pension plan) is not considered in LDI solutions. As a consequence, an LDI solution may be overly conservative. A second risk-reducing mechanism, also frequently ignored by LDI, is the postponement of indexation in case of low funded ratios. As a third factor, new pension rights may improve a weakly funded ratio if the actuarial price is paid for these rights. If these mitigating effects are ignored, the resulting asset allocation may become overly conservative given a certain long-term ambition.

This paper contributes to the existing literature by examining the consequences of LDI for life insurers. Our approach is similar to Boender ${ }^{7}$ in the sense that we use a scenario approach ${ }^{10}$ to study the effectiveness of LDI. Our results are, however, much more positive and indicate that the LDI concept has several major advantages for life insurance companies:

- Dividing the assets in an LHP and a return portfolio (RP) creates a natural benchmark for the LHP portfolio (the liabilities).

- When setting up a proper LHP, one has to explicitly address all risks embedded in insurance liabilities, including the options embedded in these liabilities.

- When the liability-driven risks are covered by the LHP, the resulting return assets can be optimised using well-known (Markowitz) optimisation techniques or (equity) hedge strategies.

In one sense, constructing LHP portfolios for life insurers is more straightforward than for pension funds since most claims are in nominal terms. The issue of hedging inflation risk is therefore of less importance (although exceptions exist, for example in the case of insured pension contracts with indexation). Complicating issues like the effect of risk-sharing with a sponsor and the effect of conditional indexation are also absent or of less importance (since typically no sponsor exists and claims are not

\footnotetext{
${ }^{7}$ Boender (2007).

${ }^{8}$ Zenios and Ziemba (2006, 2007).

${ }^{9}$ Ziemba and Mulvey (1998).

${ }^{10}$ Also known as Monte Carlo simulation of dynamic financial analysis.
} 
adjusted to inflation). Stated differently, for most insurance companies it is clear what the actual liability is and how the market value of this liability should be determined. ${ }^{11}$

In another sense, LDI portfolios for insurance companies are relatively complex compared to LHP portfolios for pension funds due to options embedded in insurance contracts. We demonstrate in this paper that matching these embedded options with the proper financial instruments (like swaptions, stock options or other hybrid instruments) is possible, although some mismatch risk can of course remain in practice. We also show that overall risk is determined to a large extent by the market value of the matching assets compared to the market value of the liabilities. If these market values are equal, overall risk is minimised. If the volume of the matching assets becomes smaller than the value of the liabilities, overall risk (and return) increases strongly because more leverage is created on the return balance sheet. After one has determined the LHP and the amount of leverage the resulting (return) assets can be optimised using familiar "asset-only" techniques.

The remainder of this paper is organised as follows. We first explain in the next section how a simple LDI balance sheet can be constructed by rearranging the assets on a separate matching and return balance sheet. We then investigate in the subsequent section how the matching assets (the LHP) can be optimised in such a way that the market value of the liabilities is replicated for a large set of economic scenarios. Using this optimised LHP, we study risk and return on the overall balance sheet in the section after that. The last section concludes.

\section{Construction LDI balance sheet}

\section{Example balance sheet}

The fair value balance sheet in Figure 1 will serve as an example in this paper.

The fair value reserve first of all consists of a basic reserve for the (expected) guaranteed premiums, costs and benefits (value: 748). We do not include an MVM to keep the analysis a simple as possible. ${ }^{12}$ For simplicity, we also do not consider new business but only the runoff of the existing policies. This is not to say that the effect of

${ }^{11}$ For example, the CRO Forum (2008) recently released a paper concerning the determination of the market value of insurance liabilities. The CRO Forum's position is that all cash flows should be separated into hedgeable and non-hedgeable components and valued using either mark-to-market or mark-to-model approaches. Components of the cash flow for which hedging instruments are available in the financial markets should be valued with reference to the prices of those instruments or using the same option pricing techniques and parameters that are used in valuing the hedge portfolio in the financial markets. For components of the cash flow that are subject to non-hedgeable risks (both financial and non-financial) a mark-to-model adjustment (the market value margin (MVM)) should be added to the best estimate value of the cash flow. A similar position is found in the latest Solvency II guidelines (see CHEIOPS, 2007).

12 The idea behind the MVM is to assess how much a (risk-averse) investor would demand in excess of the liabilities' best-estimate value in order to be compensated for all risks that cannot be hedged. Risks that can be hedged or diversified away should have no impact on the MVM. In the current Solvency II (QIS 4) guidelines, the MVM is approximated (marked-to-model) using a cost-of-capital approach (see CHEIOPS (2007) or CRO Forum (2008)). 


\begin{tabular}{|c|c|c|c|}
\hline ASSETS & & & IES \\
\hline Stocks & 285 & Surplus & 185 \\
\hline \multirow[t]{6}{*}{ Fixed income } & 665 & \multirow{2}{*}{\multicolumn{2}{|c|}{ Fair value reserve }} \\
\hline & & & \\
\hline & & - Basic reserve & 748 \\
\hline & & - Profit sharing options & 18 \\
\hline & & - Unit linked guarantee options & 45 \\
\hline & & $\begin{array}{l}\text { - Present value of fees for } \\
\text { unit linked guarantees }\end{array}$ & -45 \\
\hline Total & 951 & Total & 951 \\
\hline
\end{tabular}

Figure 1. The fair value balance sheet serving as an example in this paper.

Note: We here consider a (stylised) balance sheet of an insurance company with (i) products without additional optionalities (like simple annuities), (ii) products with additional profit-sharing based on the interest rate level and (iii) unit-linked investment contracts with guarantees. The (stylised) asset mix consists of 70 per cent fixed income and 30 per cent bonds.

new business can be ignored in practice: for going-concern (ALM) analyses this aspect should definitely be taken into account. When an insurer has selected an LDI solution it is, obviously, also extremely important to update the LHP for the existing policies with additional liability hedges when new business arrives. For brevity, we also ignore the effect of policy-holders who surrender their policy. Surrender is an important phenomenon, however, which should be considered in practice. The section "Modelling surrender" therefore explains in more detail how the effect of surrender can also be included in an LDI solution.

The insurer of this example has a significant number of insurance policies with additional profit-sharing in case of high interest rates. Because this profit-sharing component is essentially an interest rate option, an additional reserve is required (value: 18). ${ }^{13}$ There is also a reserve for embedded options in unit-linked policies (value: 45). ${ }^{14}$ These options are important when the policy-holders receive a guaranteed return on their investments or a guaranteed capital when the contract ends (insurers must compensate a shortfall with respect to such a guarantee). As a compensation for giving this guarantee, this insurer receives a fixed guarantee fee. The present value of the fees that are expected to be paid in the future by the holders of these policies (value: -45 ) currently offsets the unit-linked option reserve. ${ }^{15}$

The assets consist of 30 per cent stocks (value: 285) and 70 per cent fixed income (value: 665$)$. These assets are annually rebalanced to the initial ( 30 per cent -70 per cent)

\footnotetext{
${ }^{13}$ The profit-sharing options are priced using an adaptation of Black's option formula (see Hull, 2006).

${ }^{14}$ The unit-linked options are priced using the formula proposed by Schrager and Pelsser (2004).

${ }^{15}$ The present value of these guarantee fees may become larger (in an absolute sense) than the unit-linked reserve. In this case, this present value on the balance sheet is limited to the (absolute) value of the corresponding reserve.
} 
mix. Currently, no interest rate derivatives or stock options are used by the insurer. On the basis of this balance sheet, the insurer's surplus is equal to 185 . Because the legally required solvency level (according to the Solvency I guidelines) is equal to 46, the Solvency I ratio is equal to 398 per cent.

\section{Rearranging the balance sheet}

We now apply the LDI concept and split the balance sheet in a return and a matching balance sheet. Figure 2 shows the effect of this procedure.

As mentioned before, LDI is based on the idea that liabilities are matched as well as possible with an LHP. Fixed income thus naturally belongs to the LHP, since these assets are used to match the interest rate sensitivity of the liabilities. The remaining assets (stocks) are part of the RP.

Notice that the matching balance sheet also contains the item "fictive cash". This (fictive) cash position is needed to match the volume of the liabilities. Because (theoretically) liabilities are exactly replicated by the corresponding assets, the matching assets should have the same volume as the liabilities. A cash position, which has (almost) no interest rate sensitivity, can be used to correct a volume mismatch with

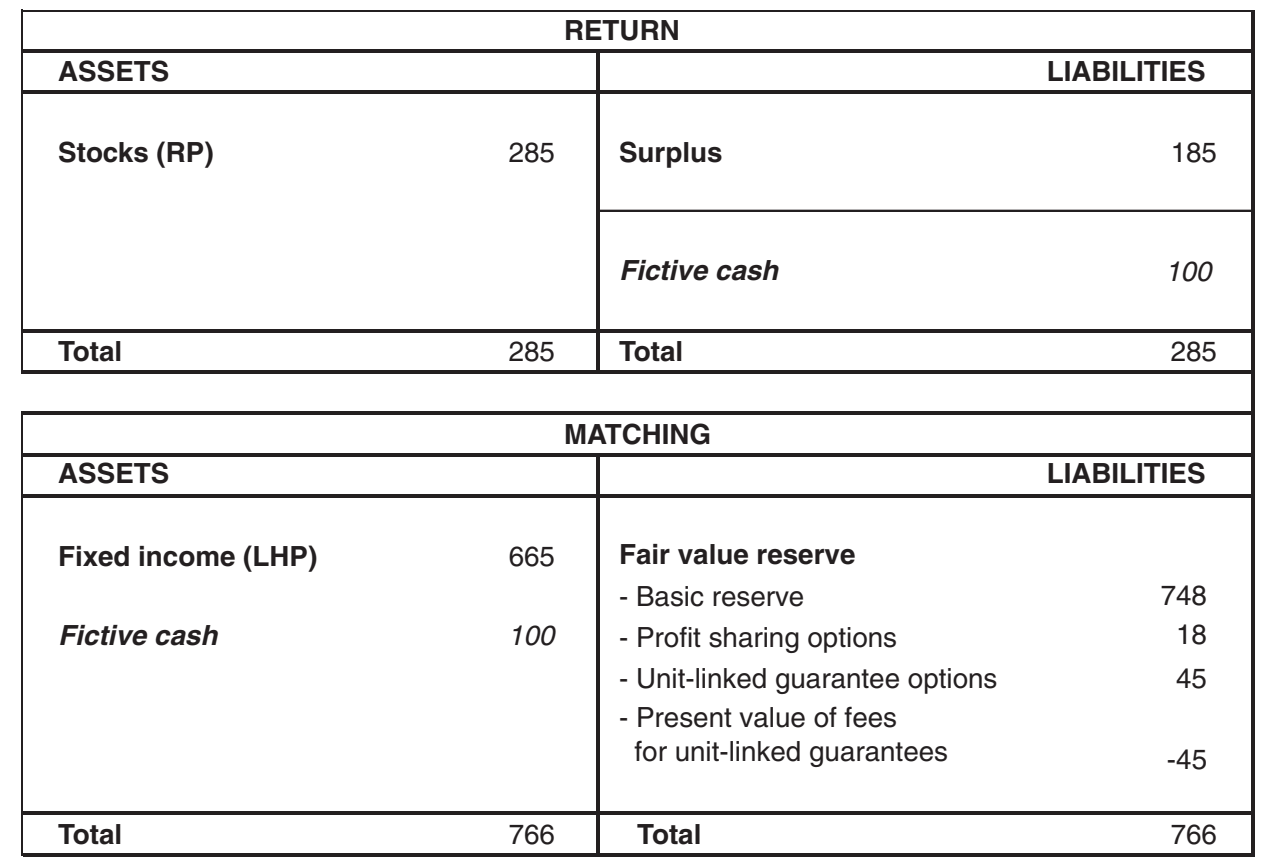

Figure 2. The insurer's balance sheet, but now from an LDI perspective.

Note: The balance sheet is divided in a matching balance sheet with the liabilities and fixed income. The other assets (stocks) and the surplus are part of the return balance sheet. Because the value of the fixed income assets is smaller than the market value of the liabilities, a fictive cash position is added to the matching balance sheet. This causes a short cash position (i.e., leverage) on the return balance sheet. 
the liabilities without interfering with the interest rate hedges in the LHP. Note that this cash position also appears on the return balance sheet, but on the opposite side. This implies that we effectively create more leverage on the return balance sheet when the volume mismatch on the matching balance sheet increases. Due to this added leverage, the risk (and the expected return) on the return balance sheet increases.

\section{Modelling credits}

The above picture changes if the fixed income investments (partly) consist of credits. These more risky investments can, however, also be modelled within an LDI framework by decomposing them in a risk-free (Treasury bond) portfolio plus a stochastic excess term that models the additional risk and return associated with credit bonds. This stochastic excess term can be modelled conveniently in the RP with a long credits - short Treasury position. An example is given in Figure 3.

We here assume that 50 per cent of all fixed income investments consists of credits. The balance sheet item "Fictive Treasury" in the LHP here stands for a portfolio of risk-free Treasury bonds with the same underlying maturities as the credit portfolio. The long credits - short fictive Treasury position in the RP models the stochastic excess term associated with credits.

\begin{tabular}{|c|c|c|c|}
\hline \multicolumn{4}{|c|}{ RETURN } \\
\hline ASSETS & & & LIABILITIES \\
\hline Stocks (RP) & 285 & Surplus & 185 \\
\hline Credits (long) (RP) & 333 & & \\
\hline Fictive Treasury (short) (RP) & -333 & Fictive cash & 100 \\
\hline Total & 285 & Total & 285 \\
\hline \multicolumn{4}{|c|}{ MATCHING } \\
\hline ASSETS & & & LIABILITIES \\
\hline Fixed income (LHP) & 333 & $\begin{array}{l}\text { Fair value reserve } \\
\text { - Basic reserve }\end{array}$ & 748 \\
\hline Fictive Treasury (LHP) & 333 & - Profit sharing options & 18 \\
\hline Fictive cash & 100 & $\begin{array}{l}\text { - Unit-linked guarantee options } \\
\text { - Present value of fees } \\
\text { for unit-linked guarantees }\end{array}$ & $\begin{array}{r}45 \\
-45\end{array}$ \\
\hline Total & 766 & Total & 766 \\
\hline
\end{tabular}

Figure 3. The effect of credits on the return and matching balance sheet.

Note: We here decompose the credit portfolio in a risk-free Treasury bond portfolio and a stochastic excess term. The fictive Treasury bonds are placed in the LHP; the stochastic excess term is modelled in the RP with a long-short position. 


\section{Modelling surrender}

In practice, the construction of LDI portfolios for life insurers is complicated due to embedded surrender options. For example, policy-holders in Europe are often able to surrender their policy in return for the book value of their policy (although hefty penalties may apply). This creates an incentive to surrender the policy when the market interest rate is high and the book value of the contract exceeds the market value.

This embedded option, when exercised, can lead to a significant outflow of funds. Amenc et al. ${ }^{5}$ therefore correctly remark that "good risk management should cover this risk". They also remark that in practice it is difficult to precisely calibrate the scenario-depending surrender cash flows due to limited historical data on the behaviour of policy-holders. Given a calibrated model, an LDI portfolio could be constructed, however, which counteracts the effect of surrender. Such a portfolio should consist of interest rate derivatives, like caps of (payer) swaptions, which (approximately) mimic the contingent surrender cash flows for high interest rate scenarios. For the construction of an appropriate portfolio with caps and swaptions a replicating portfolio technique can be used. For more information about this technique, see Oechslin et al. ${ }^{16}$ and Schrager. ${ }^{17}$

\section{Construction of an LHP}

\section{First analysis}

We now analyse the effectiveness of the simple LHP as specified in Figure 2 (i.e., without credits). The value of the fixed income assets plus the fictive cash position should (theoretically) be equal to the value of the liabilities for all future scenarios. In other words, the surplus of the matching balance sheet should always be equal to zero. As a test, we generate 1,000 scenarios for interest rates and stock returns and analyse the evolution of the surplus of the matching balance sheet. Figure 4 shows the results of this stochastic simulation.

Obviously, this simple LHP is not robust with respect to future economic developments. Especially note the negative impact of a decreasing interest rate on the surplus. For example, for the selected economic scenario the surplus drops to almost -650 in 2012 (see Panel B). This scenario is a typical example of a low interest rate scenario (see Panel A).

To further analyse the interest rate sensitivity of this insurer we evaluate the effect of a (parallel) change of the interest rate curve at the current point of time (2007). Figure 5 shows how the different items of the matching balance sheet change for changes in between -4 per cent and +4 per cent.

\footnotetext{
16 Oechslin et al. (2007).

17 Schrager (2008).
} 

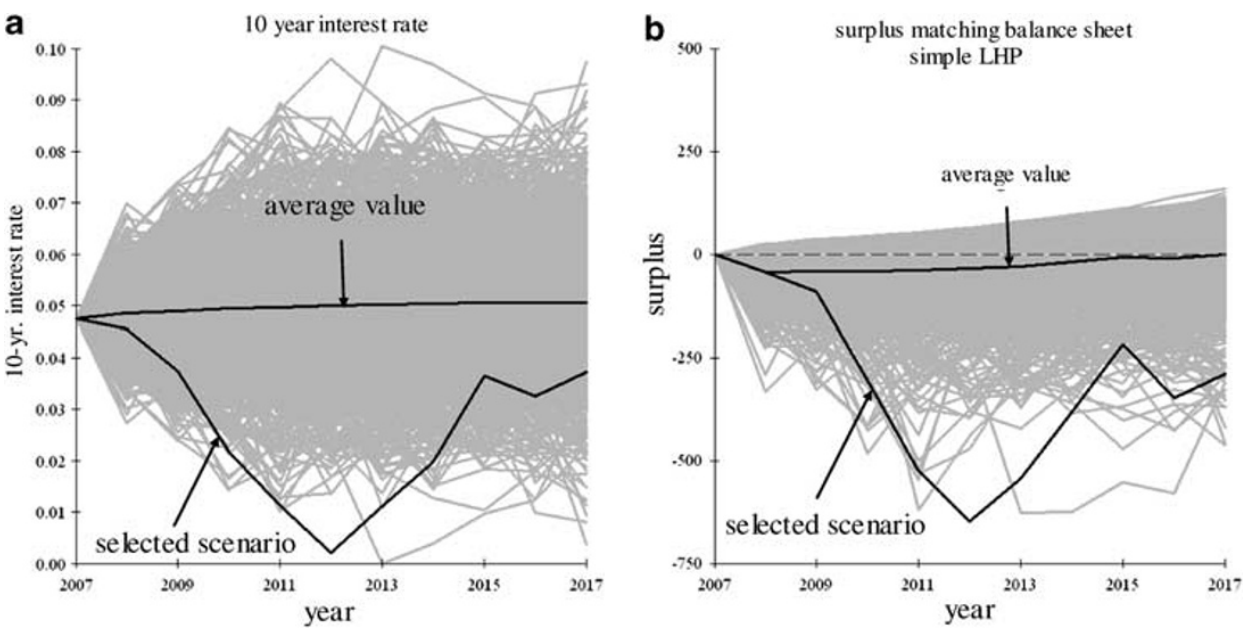

Figure 4. Evolution of the surplus of the matching balance sheet.

Note: We here consider 1,000 different economic scenarios. Note the negative impact of a decreasing interest rate on the surplus.

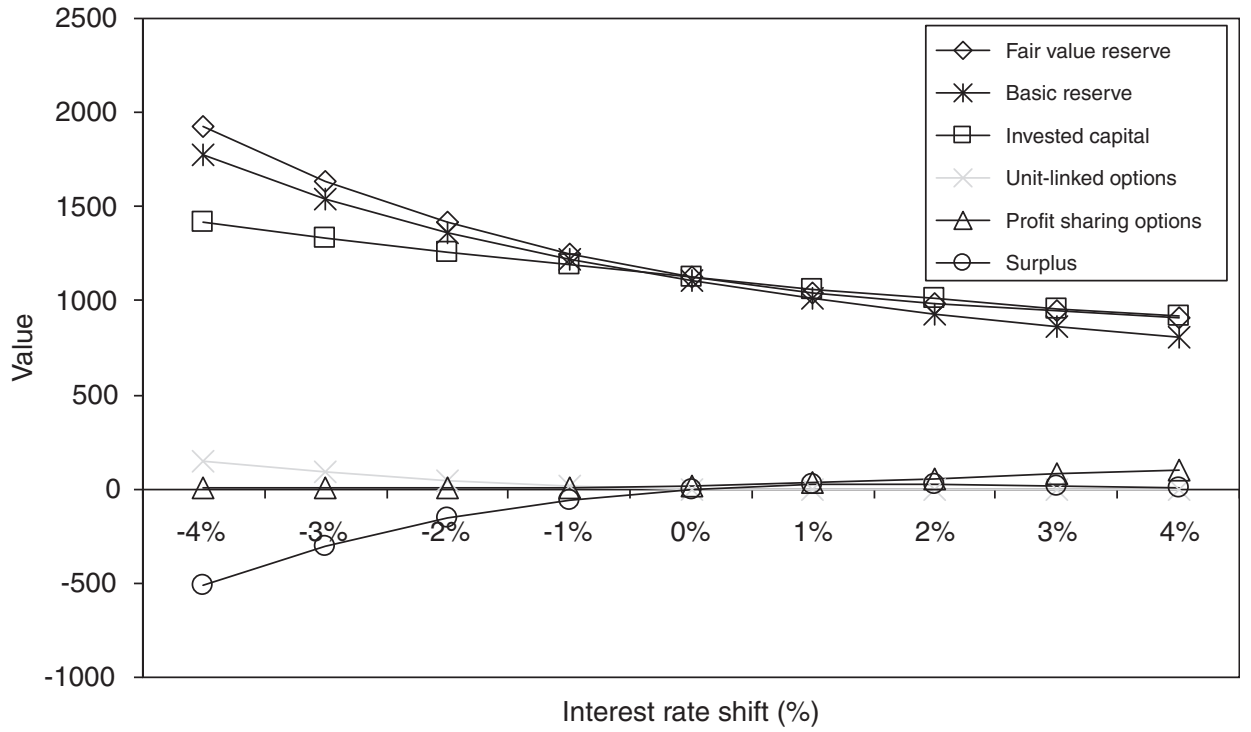

Figure 5. The impact of parallel shifts of the interest rate curve on the matching balance sheet. Note: Note that the interest rate mismatch between assets and liabilities becomes large for low interest rates.

The item "Unit-linked options" is here equal to the sum of balance sheet items "Unit-linked guarantee options" and "Present value of fees for unit-linked guarantees". Figure 5 clearly shows that there is a large interest rate mismatch between the assets and liabilities, resulting in a strongly negative surplus for low interest rates. 


\section{Minimising the duration mismatch}

We now add a layer of interest rate swaps to the LHP to mitigate the interest rate risk. These swaps are bought a pari (i.e., they require no initial investment) and have a range of maturities $(1-10,12,15,20$ and 30 years) to properly match the interest sensitivity for different segments ("buckets") of the interest rate curve. We select those swaps that minimise the duration mismatch of the assets in the LHP (fixed income plus the additional swaps) with the basic reserve (the guaranteed cash flows). The effect of this swap construction is shown in Figure 6. The interest rate sensitivity of the basic reserve is now properly matched at the current point in time and a negative surplus is only caused by high option values for low or high interest rates.

In Figure 7 we study the impact of this swap construction in a stochastic simulation. In this simulation we also add an additional swap (with a maturity of 30 years) in each simulation year to further refine the initial interest rate hedge. These additional swaps are also bought a pari. Figure 7 shows that the risk reduction of the swap construction is large. Note that the interest rate risk of the embedded options is also mitigated because we match the duration annually with a 30-year swap. This method does not remove the interest rate risk completely, however, since swaps are only effective for small interest rate changes.

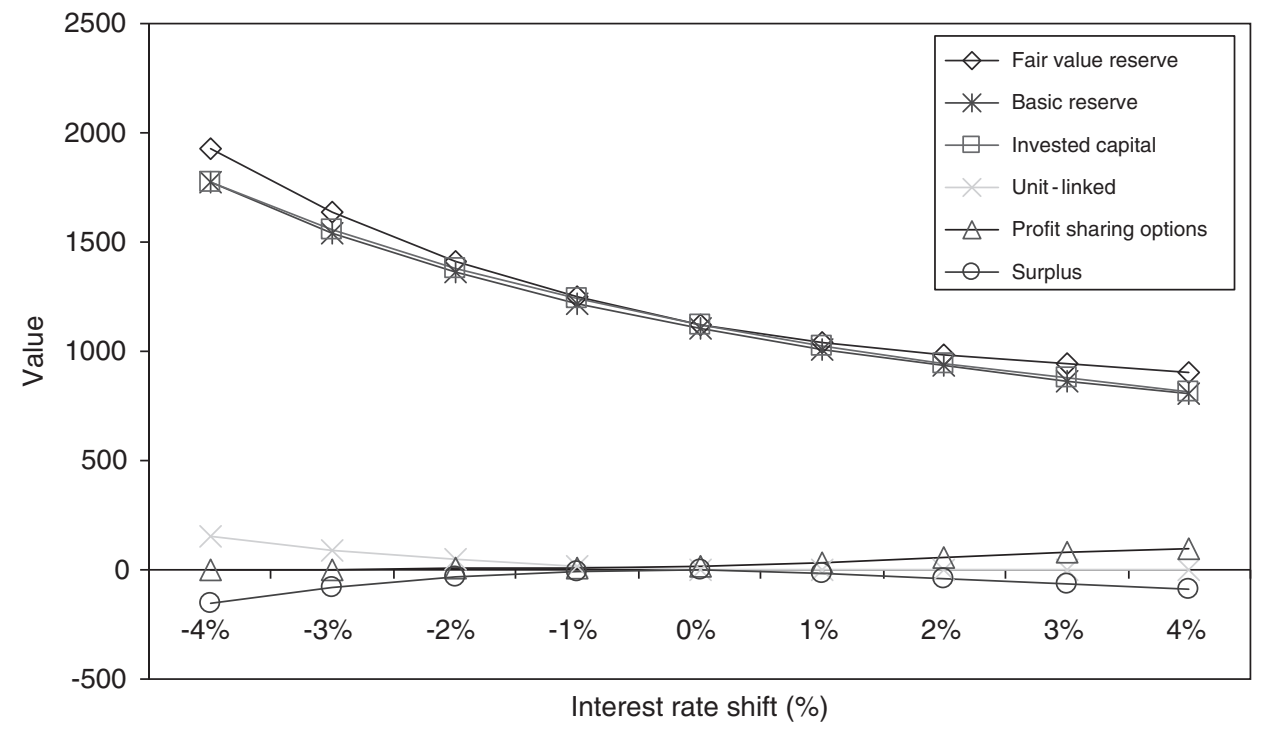

Figure 6. The impact of an additional swap construction on the interest rate sensitivity of the matching balance sheet.

Note: The interest rate sensitivity of the basic reserve is now matched using the existing fixed income assets and an additional layer of swaps. 

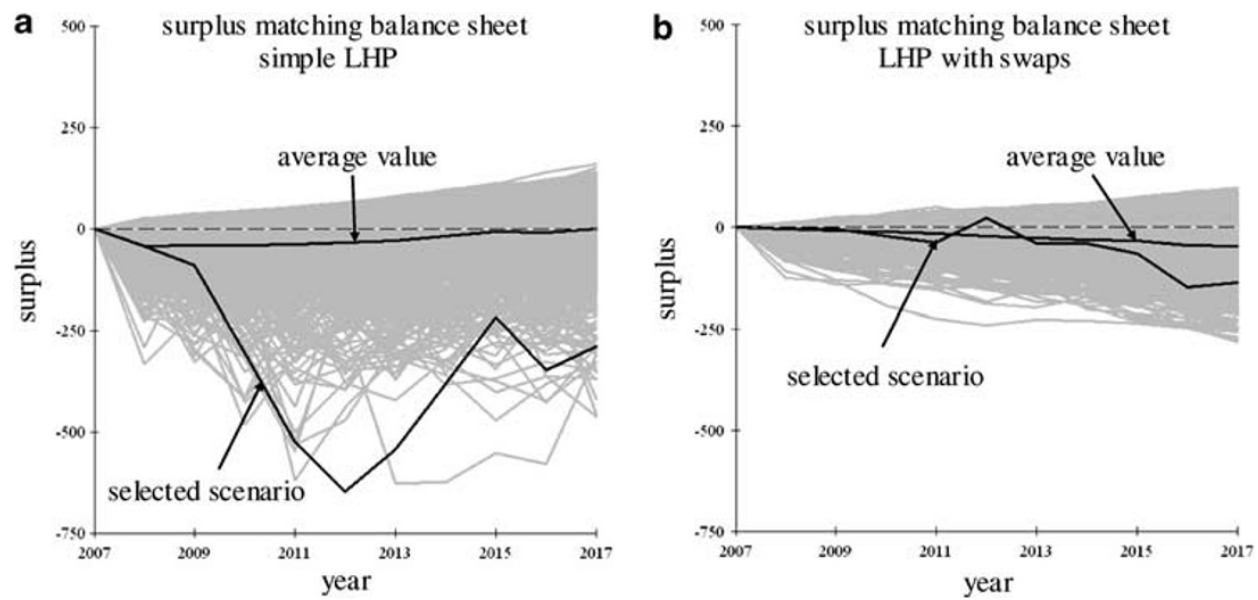

Figure 7. Evolution of the surplus of the matching balance sheet when an additional swap construction is used.

Note: Notice the significant risk reduction when swaps are part of the LHP (see Panel B).

\section{Hedging the embedded insurance options}

Because the guaranteed cash flows are now adequately matched, the remaining risks at the matching balance sheet are caused by the unit-linked and profit sharing options. The most important risk at this point is the sensitivity of the (net) unit-linked option to the price of the underlying stocks. This sensitivity is illustrated in Figure 8.

For the selected scenario the stock index performs poorly in the long run (see Panel B). This results in an increasing unit-linked option value (see Panel C) and a dropping surplus on the balance sheet (see Panel D). Averaged over all scenarios, the correlation between the stock returns and changes in the surplus is significantly positive $(\approx 0.5)$, which confirms that negative stock returns are an important risk factor on the matching balance sheet.

We study the effect of (partly) hedging the option risks in the unit-linked portfolio in Figure 9. When we hedge 50 per cent of the unit-linked option, at each point in time 50 per cent of the option value and 50 per cent of the option cash flows are matched. A 100 per cent option hedge exactly matches the embedded option. We assume that these synthetic hedges are financed by selling some of the fixed income assets. Note that Panels B, C and D of Figure 9 consist of percentile plots instead of scenario plots. The 5 per cent percentile line indicates that 5 per cent of the 1,000 scenarios (i.e., 50 scenarios) are located below this line. The lower percentiles (e.g., for 5 per cent and 10 per cent) clearly shift upwards when the unit-linked option is hedged. The downward risks are thus significantly reduced.

Due to the nature of the unit-linked guarantee option (a combined equity -interest rate option) this hedge portfolio in practice often consists of a mixture of equity put 
a
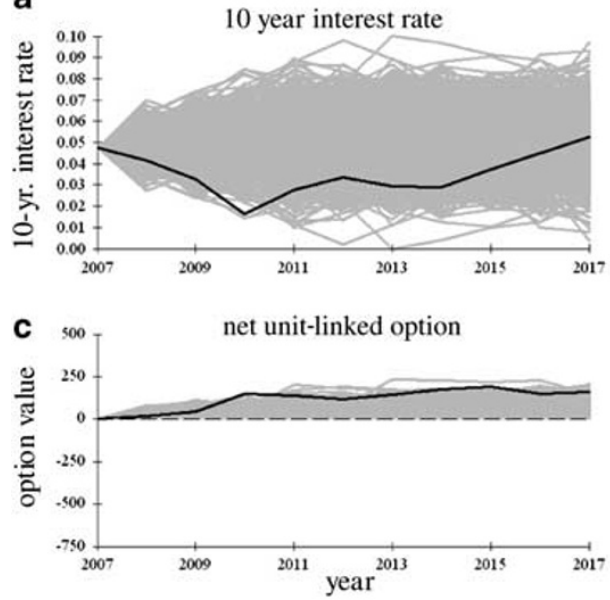

b
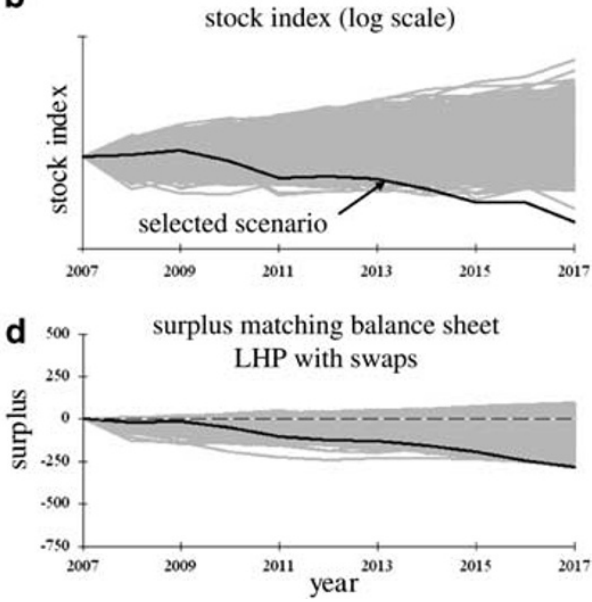

Figure 8. The impact of low equity returns on the surplus of the matching balance sheet.

Note: Notice the increasing value of the unit-linked option (see Panel C) for a dropping stock index (see Panel B). This results in a significant decrease of the surplus of the matching balance sheet (see Panel D).

a

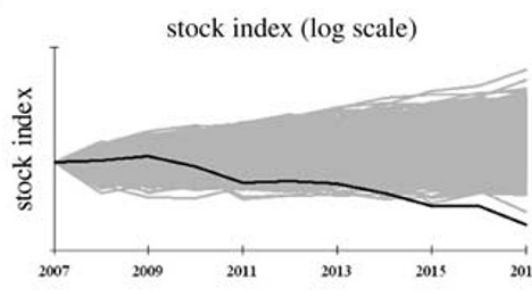

C surplus matching balance sheet

LHP with swaps

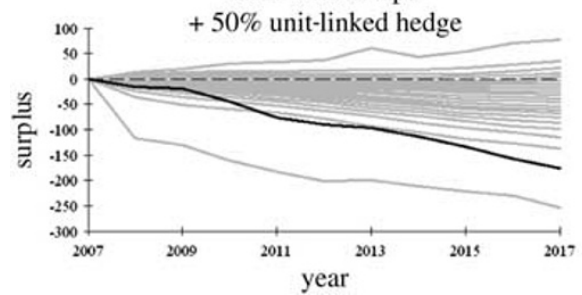

b surplus matching balance sheet

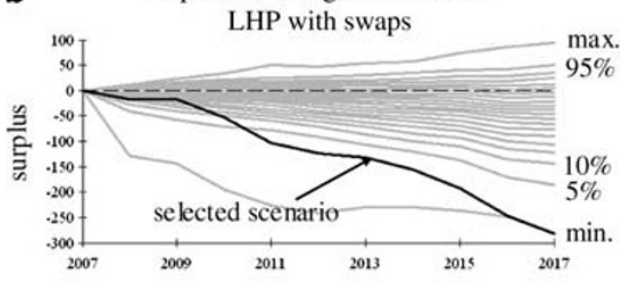

d surplus matching balance sheet

LHP with swaps

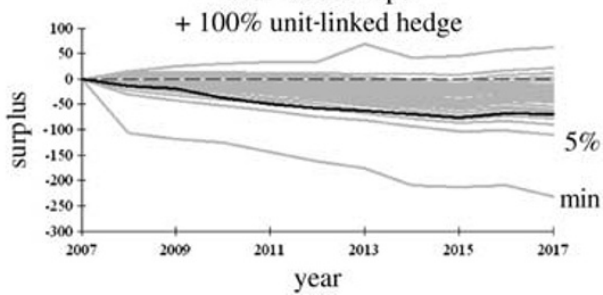

Figure 9. The effect of hedging the unit-linked option on the evolution of the surplus on the matching balance sheet.

Note: Note that Panel B, C, and D consist of percentile plots instead of scenario plots. By comparing the lower percentiles it becomes clear that the downside risks decrease when the unit-linked option is hedged. 

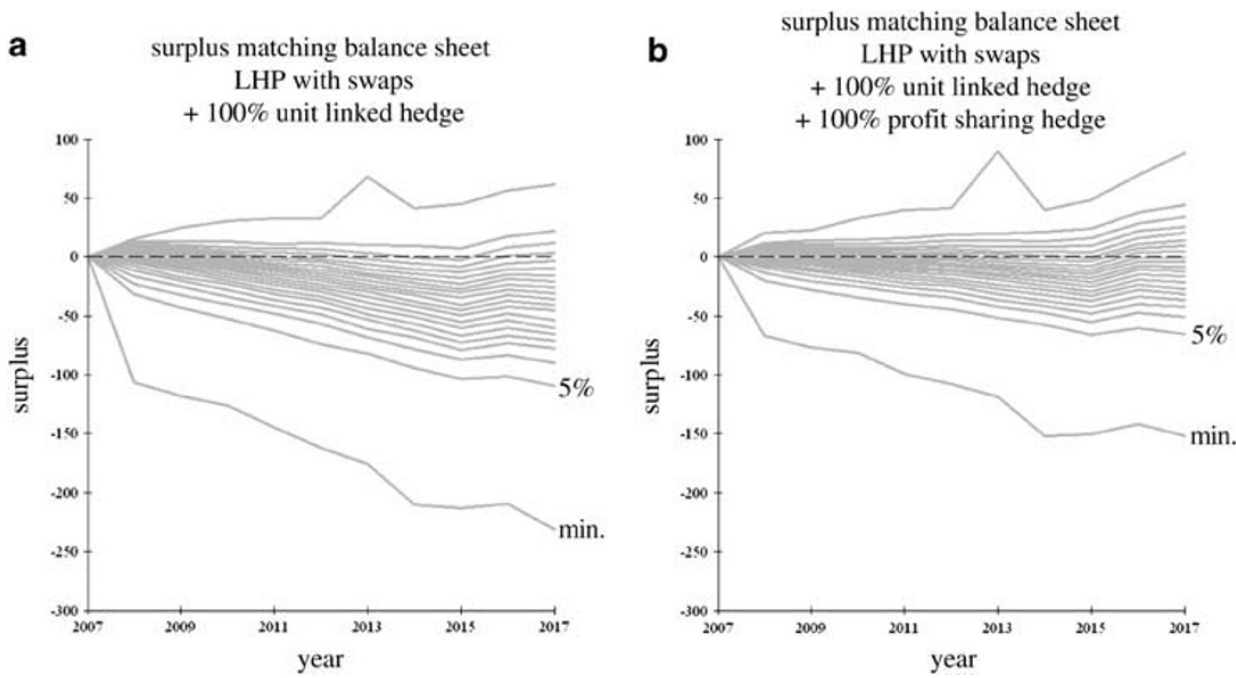

Figure 10. The effect of hedging the profit-sharing option on the evolution of the surplus.

Note: This percentile plot shows that the downside risks further decrease when this option is hedged.

options and (receiver) swaptions. ${ }^{18}$ Hybrid derivatives may be a cost efficient alternative as well. See, for example, the recent paper by Walschots and Van Capelleveen ${ }^{19}$ who demonstrate that the downside risk of a pension fund can be hedged efficiently using a receiver swaption whose strike is depending on the stock market index. If the stock market drops, the strike of this swaption increases and the protection against decreasing interest rates improves. The advantage of this form of protection is that only the true risk scenarios (a combination of a low stock level and a low interest rate) are hedged. This may be cheaper than hedging the interest rate and equity risk separately.

We continue with the final risk source on the matching balance sheet: the profitsharing option. This is a pure interest rate option. The percentile plot in Figure 10 shows that the risk on the matching balance sheet further reduces when we hedge these risks as well. The remaining mismatch risk is small and mainly due to the simple duration matching procedure (only once a year a new swap is bought). We have again used a synthetic option here, which exactly matches the option cash flows (and option values). Additional experiments show that in practice a good profit-sharing hedge can also be constructed using a set of payer swaptions. ${ }^{20}$

${ }^{18}$ In essence, we want to replicate this embedded insurance option as well as possible with financial instruments. This replicating portfolio approach has been advocated recently by different authors. For more information, see Oechslin et al. (2007) and Schrager (2008). In additional experiments (not reported here) we verified that a good hedge of the unit-linked option is possible using liquid financial instruments.

${ }^{19}$ Walschots and Van Capelleveen (2008).

${ }^{20}$ Payer swaptions can be used to hedge the profit-sharing option because (ignoring the unit-linked option) 


\section{Conclusions}

We started with the simple LHP in Figure 2, consisting of only a fixed income portfolio in combination with a fictive cash position. We found that the mismatch of this portfolio with the actual liabilities is huge due to: (i) a duration mismatch; and, (ii) profit-sharing and guarantee options that are embedded in the liabilities. The duration mismatch can be minimised efficiently using a layer of (linear) swap contracts. In addition, a 30-year swap is bought in each future year to update this initial hedge. The embedded options can be matched by (nonlinear) products such as payer swaptions (for the profit-sharing option) or a mixture of receiver swaptions and equity put options (or hybrid options) for the unit-linked guarantees.

The resulting, optimal LHP portfolio is shown in Figure 11. It is important to note that with a relatively modest investment (63) the downside risks on the matching balance sheet can be reduced significantly. This is illustrated in Figure 12, where we compare the quality of the initial LHP portfolio with fixed income (see Figure 2) with the optimised LHP (see Figure 11).

Interestingly, the added option hedges do not appear to have a negative impact on the average surplus on the matching balance sheet (compare the average values in Panels A and B). In fact, the average surplus increases slightly because the strongly negative scenarios are almost entirely eliminated (the upside scenarios are also suppressed, but this effect is less pronounced). Setting up a proper LHP portfolio thus appears to be very attractive: the downside risks are suppressed significantly, while the average return of the LHP (plus the fictive cash position) remains sufficiently high to match the expected return of the liabilities.

\section{Analysis of complete balance sheet}

We now proceed with an analysis of the complete balance sheet. For simplicity, we consider the stylised situation in which the insurer does not pay taxes or dividends. The results are shown in Figure 13.

Panel A shows the evolution of the surplus in case of the original balance sheet in Figure 1. Results in Panel B (for the return-matching balance sheet in Figure 2) are quite similar because the underlying assets and liabilities are the same. Small differences occur, however, because (annual) rebalancing has a different effect when we consider a single balance sheet with annual rebalancing (as in Panel A) or two different balance sheets (as in Panel B). Panel C clearly shows the effect of the optimised LHP in Figure 11: the downside risks are reduced significantly.

To further reduce the risks, we can reduce the percentage of stocks and invest more money in fixed income. This has almost no impact on the risks on the matching 


\begin{tabular}{|c|c|c|c|}
\hline \multicolumn{4}{|c|}{ RETURN } \\
\hline ASSETS & & & TIES \\
\hline \multirow[t]{2}{*}{ Stocks (RP) } & 285 & Surplus & 185 \\
\hline & & Fictive cash & 100 \\
\hline Total & 285 & Total & 285 \\
\hline
\end{tabular}

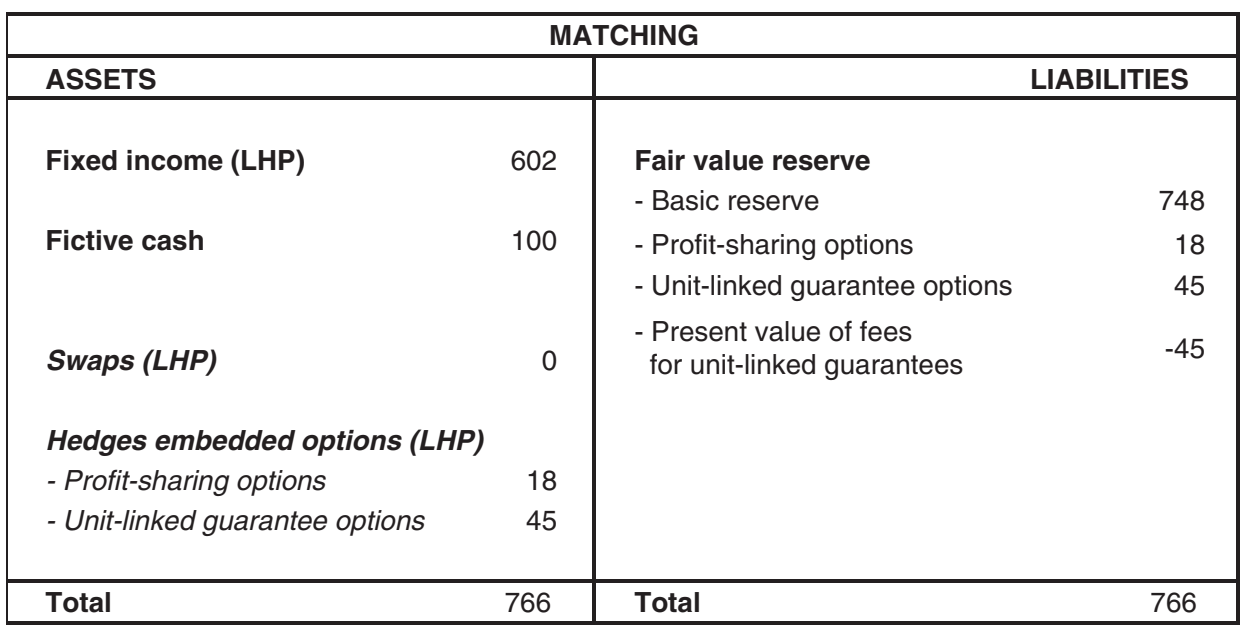

Figure 11. LDI balance sheet with the optimised LHP portfolio.

Note: A layer of swaps is bought a pari (i.e., without an initial investment) to match the duration of the LHP with the duration of the basic reserve. In addition, a 30-year swap is bought in each future year to update this initial hedge (these instruments are not visible on the initial balance sheet). The embedded (profit-sharing and unit-linked) options are hedged using synthetic options which mimic the behaviour of the embedded options in the liabilities.

balance sheet because the interest rate risks are minimised by the swap construction in the LHP. ${ }^{21}$ The impact on the RP balance sheet is significant, however, because the amount of leverage decreases (as well as the allocation to stocks). This effect is illustrated in Figure 14, where we show the evolution of the surplus on the matching and total balance sheet.

In Panels $\mathrm{A}$ and $\mathrm{C}$ we consider the situation in Figure 11, where 87 per cent of the volume of the liabilities is matched with fixed income. In Panels B and D we consider the situation where 100 per cent of the volume of the liabilities is matched (i.e., fixed income has a value of 766 and stocks a value of 185). Comparing Panel C with Panel D shows that the downside (stock) risk decreases when we reduce the amount of leverage

${ }^{21}$ The initial swap portfolio is (slightly) adjusted because more fixed income is available on the matching balance sheet in this case. 

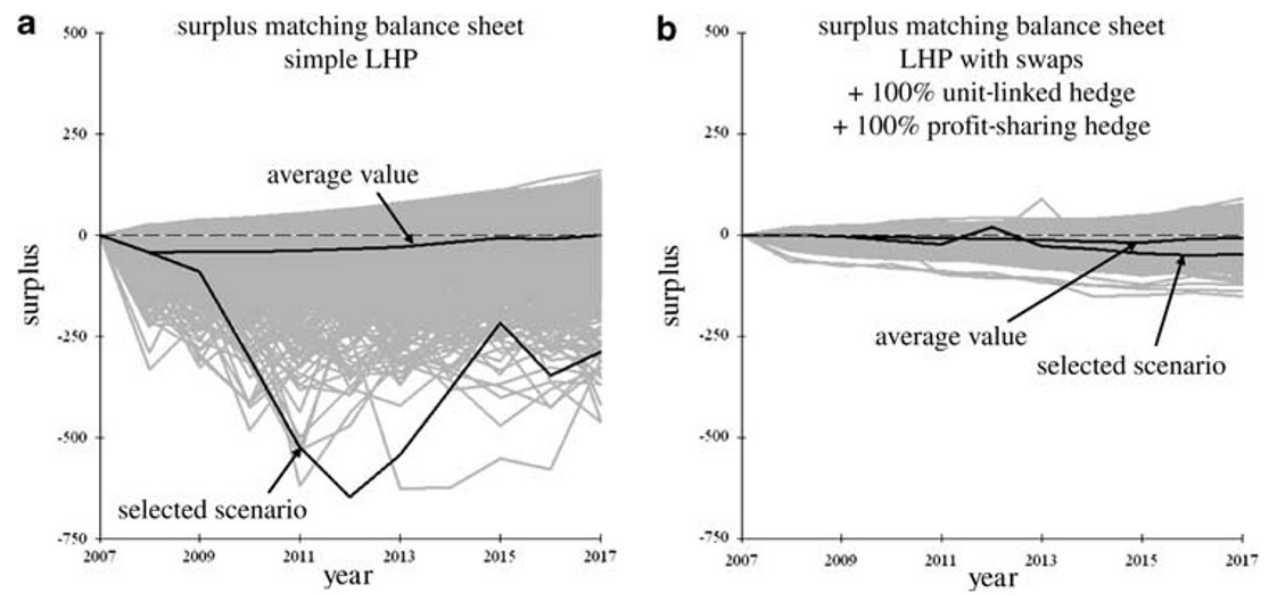

Figure 12. A comparison of the quality of the simple LHP and the optimised LHP.

Note: Note that the downward risks on the matching balance sheet are reduced significantly by adding swaps and hedges for the unit-linked and profit-sharing options in the liabilities.
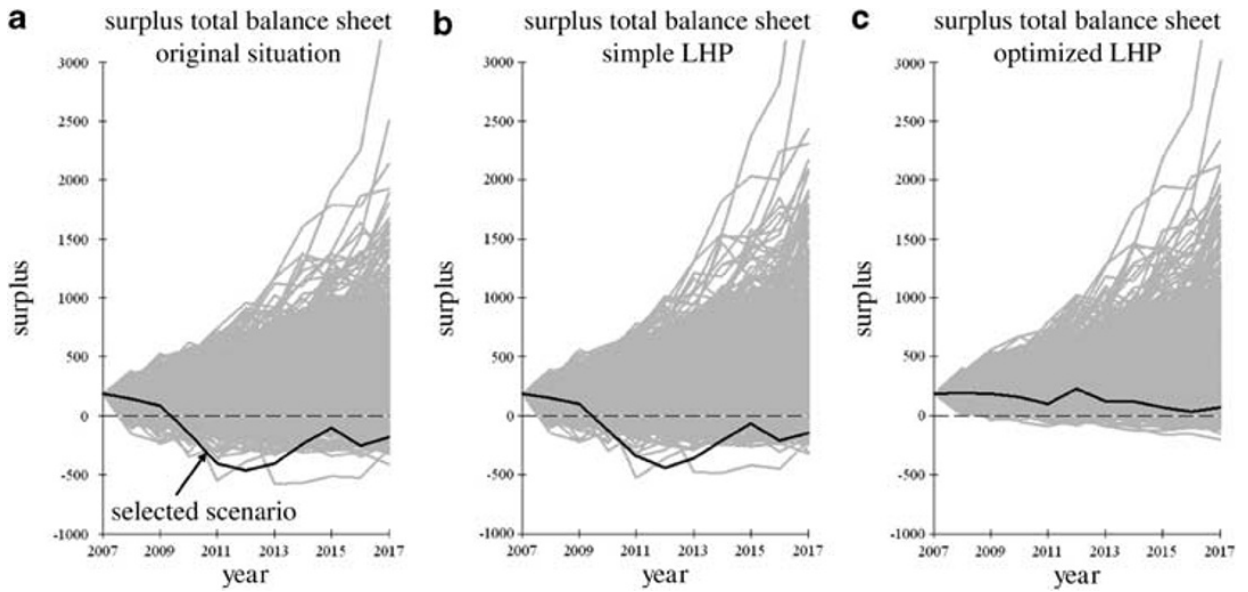

Figure 13. Evolution of the surplus for 1,000 different economic scenarios.

Note: We here consider the original balance sheet (see Figure 1), the simple LDI balance sheet in Figure 2 and the optimised LDI balance sheet in Figure 11. Note that the downward risks decrease significantly when we optimise the LHP (see Panel B and C).

(and the exposure to stocks). This, however, has a negative impact on the return: the average surplus after ten years is lower in Panel D than in Panel C. The average return on the surplus also decreases: from 9.7 per cent to 8.3 per cent.

It is possible to further reduce the downward surplus risks using an appropriate (put or collar) stock option strategy. As an example, we evaluate results for two different put option strategies. The first put strategy protects 100 per cent of the stock portfolio with a three-year put option. The strike of this option is equal to 70 per cent of the 

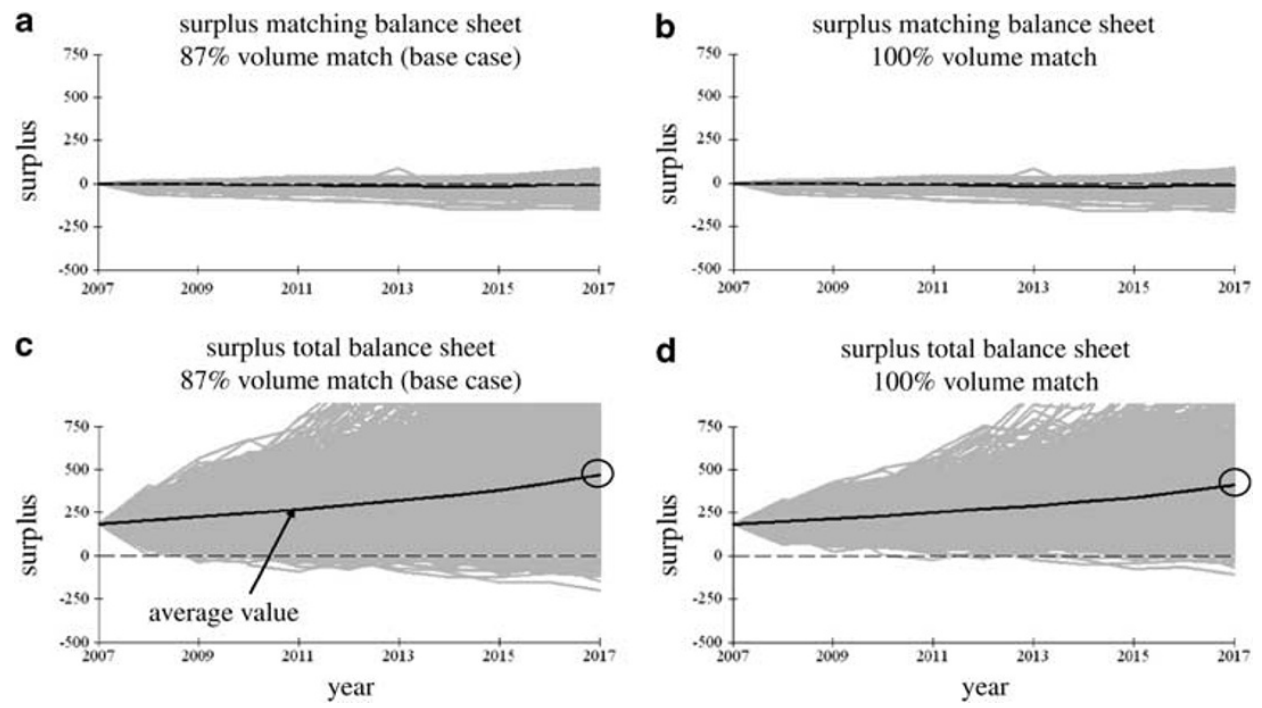

Figure 14. Impact of the volume of the liabilities that is matched by the LHP.

Note: In Panel B and D the volume of the liabilities is completely matched with fixed income. This has almost no effect on the mismatch risk on the matching balance sheet (compare Panel A with Panel B). The effect on the total balance sheet is significant, however, because leverage on the RP balance sheet is eliminated in Panel B and D and the allocation to stocks decreases. This reduces both the downside risk and the expected return.

index level. The second put strategy consists of protecting 50 per cent of the stock portfolio with a one-year put option. The strike of this option is equal to 95 per cent of the index level. All options are financed by selling a part of the stock portfolio. When an option expires a similar option is bought. The options are priced using the familiar Black and Scholes ${ }^{22}$ formula. For the Black-Scholes volatility we use the scenario volatility plus a surcharge. This surcharge represents the (average) difference between the $(\log )$ volatility of the underlying index and the (implied) volatility of traded options. We use an estimate of 3.8 per cent point for this parameter, based upon empirical research for index options by Driessen et al. ${ }^{23}$

Results for these put strategies are shown in Figure 15. Panel B is the reference situation and shows the evolution of the surplus for the optimised LDI balance sheet in Figure 11. In Panel $\mathrm{C}$ we study the effect of adding the three-year put option strategy to the stock portfolio on the return balance sheet. Panel D shows the results for a one-year put option strategy. Note the significant risk-reduction in Panels $\mathrm{C}$ and $\mathrm{D}$, especially in the first years. For example, the selected stock index scenario in Panel A has a large negative effect on the surplus in Panel B in the first years. This effect is mitigated in Panels $\mathrm{C}$ and $\mathrm{D}$ due to the protection by the put option. In the long run, the risk-reducing effect of both option strategies becomes smaller. A solution might be

\footnotetext{
${ }^{22}$ Black and Scholes (1973).

${ }^{23}$ Driessen et al. (2010).
} 
a
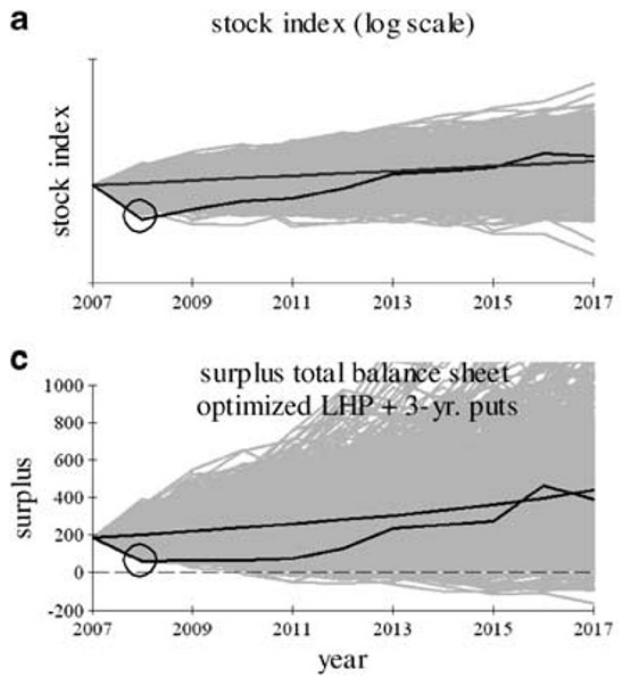

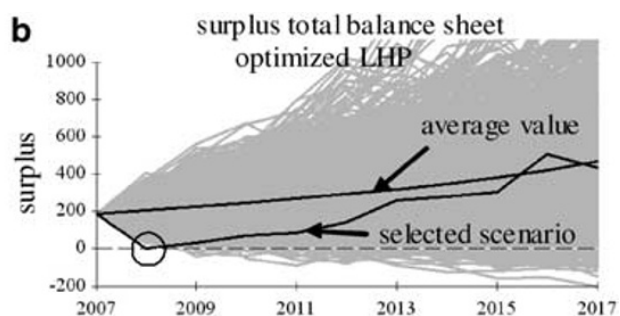

d

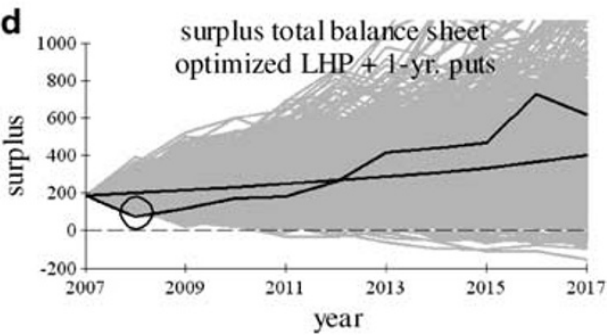

Figure 15. The effect of two different put option strategies on the evolution of the surplus on the total balance sheet.

Note: Panel B shows the evolution of the surplus for the optimised LDI balance sheet in Figure 11. In Panel $\mathrm{C}$ and $\mathrm{D}$ we study the effect of adding a put option strategy to the stock portfolio on the return balance sheet. In Panel $\mathrm{C}$ we protect 100 per cent of the stock portfolio with a three-year put option. The strike of this option is equal to 70 per cent of the index level. In Panel D we protect 50 per cent of the stock portfolio with a one-year put option. The strike of this option is 95 per cent of the index level. Note the risk-reduction in Panel C and D, especially in the first years.

to use options with a long maturity (e.g., with a maturity of more than five years). The market liquidity for such options is very limited, however, so option strategies with short maturity options are often favoured in practice.

The impact on the return on equity is negative for both put strategies: the average surplus after ten years is significantly lower in Panels C and D than in Panel D. The average return on the surplus also decreases significantly: from 9.7 per cent in Panel B to 9.0 per cent in Panel C and 8.0 per cent in Panel D. The risk reduction thus clearly comes at the cost of a lower return on equity. It should also be noted that the implementation of a protective put strategy should be done with care. The option prices (implied volatilities) vary constantly and can reach very high levels when protection is needed most (i.e., during downfalls of the stock markets). It is thus advisable to use a layered option strategy to avoid that all options should be renewed at the same point in time.

It is, of course, also useful to construct a more diversified RP, for example by using (Markowitz) optimisation techniques. ${ }^{24}$ This approach is well established and is therefore not explored further in this paper.

\footnotetext{
${ }^{24}$ See for example Steenkamp (2005).
} 


\section{Conclusions}

The LDI concept can be used to divide the asset allocation problem for a life insurer into separate, more tractable problems. This improves the (complicated) asset allocation decision. The basic idea behind LDI is to split the balance sheet into two separate balance sheets: one for the liabilities and the matching assets and one for the other (return) assets and the surplus.

Using a realistic example, we show how an insurer can match the liabilities, including all embedded options, using an LHP in combination with a (fictive) cash position. The fictive cash position also emerges as a short cash position (i.e., leverage) on the return balance sheet. We demonstrate that setting up a proper LHP portfolio is very attractive because the liability-driven risks are suppressed significantly while the average return of the LHP (plus the fictive cash position) remains sufficiently high to match the expected return of the liabilities.

The final step is an optimisation of the assets on the return balance sheets. Since the liability-driven risks are already suppressed by the matching assets, these assets can be optimised using well-known (Markowitz) optimisation techniques or (equity) hedge strategies. The LDI approach thus stimulates insurers to address all risks embedded in the insurance liabilities and facilitates the subsequent optimisation of the return assets.

\section{References}

Amenc, N., Martellini, L., Foulquier, P. and Sender, S. (2006) The impact of IFRS and Solvency II on assetliability management and asset management in insurance companies (November), EDHEC Risk and Asset Management Research Centre.

Amenc, N., Martellini, L. and Ziemann, V. (2007) Asset-liability management decisions in private banking, (February), EDHEC Risk and Asset Management Research Centre.

Boender, G. (2007) 'Investors must approach LDI with caution', Global Pensions, March, p. 24.

Black, F. and Scholes, M. (1973) 'The pricing of options and corporate liabilities', Journal of Political Economy 81(3): 637-654.

CHEIOPS (2007) 'QIS4-Technical Specifications', CEIOPS-DOC-23/07.

CRO Forum (2008) Market value of liabilities for insurance firms, July.

Driessen, J., Maenhout, P. and Vilkov, G. (Forthcoming) 'Option-implied correlations and the price of correlation risk', Journal of Finance.

Hull, J.C. (2006) Options, Futures, \& Other Derivatives, 6th edn. Upper Saddle River, NJ: Prentice Hall.

Maton, B. (2007) 'A term with many different meanings', Financial Times, 20 April.

Mindlin, D. (2006) 'The myth of the liability benchmark', Global Pensions, October, pp. 16-17.

Oechslin, J., Aubry, O., Aellig, M., Käppeli, A., Brönnimann, D. and Tandonnet, A. (2007) 'Replicating embedded options in life insurance policies', Life \& Pensions Magazine, February.

PIMCO (2007) 'Bond Basics: Liability-driven Investing', from http://europe.pimco.com/LeftNav/Bond+ Basics/2006/Liability-Driven + Investing.htm , accessed 8 June 2009.

Schrager, D. (2008) 'Replicating portfolios for insurance liabilities', Aenorm 59: 57-61.

Schrager, D.F. and Pelsser, A.A.J. (2004) 'Pricing rate of return guarantees in regular premium unit-linked insurance', Insurance: Mathematics and Economics 35(2): 369-398.

Steenkamp, T. (2005) Asset Allocation and Portfolio Construction, Driebergen, The Netherlands: Riskmatrix. Towers Perrin (2006) 'Solvency II-Introductory Guide', June, CEA Insurers of Europe.

Van Bragt, D., Steehouwer, H. and Waalwijk, B. (2010) 'Market-consistent ALM for life insurers-Steps toward Solvency II', The Geneva Papers on Risk and Insurance-Issues and Practice 35(1): 92-108.

Walschots, B. and Van Capelleveen, H. (2008) 'Hybride bescherming', VBA Journaal 2: 40-47, (in Dutch).

Zenios, S.A. and Ziemba, W.T. (2006) (eds.) Handbook of Asset and Liability Management, Vol. 2, (1) in Series of Handbooks in Finance, North-Holland, The Netherlands: Elsevier Science. 
Zenios, S.A. and Ziemba, W.T. (2007) (eds.) Handbook of Asset and Liability Management, Vol. 2, (1) in Series of Handbooks in Finance, North-Holland, The Netherlands: Elsevier Science.

Ziemba, W.T. and Mulvey, J.M. (1998) (eds.) Worldwide Asset and Liability Management, Cambridge: Cambridge University Press.

\section{About the Authors}

David D.B. van Bragt (1969) studied Physics and Philosophy. In 1998 he received a $\mathrm{PhD}$ degree in nuclear reactor physics (cum laude). He then worked for four years at the Centre for Mathematics and Computer Science (CWI) in Amsterdam. Since 2004 he is employed at Ortec Finance in Rotterdam, the Netherlands, as a consultant for the insurance risk management department. His areas of expertise are asset and liability management and risk-neutral scenario models. He is also a regular guest teacher at several Dutch universities.

Dirk-Jan Kort (1978) has studied Computational Mechanics at the University of Groningen. He then started in Groningen with his $\mathrm{PhD}$ thesis in the field of computational fluid dynamics. Since 2006, he is also employed at Ortec Finance bv in Rotterdam, the Netherlands, as a consultant for the insurance risk management department. Since 2010, he works as a software developer at Ortec Finance on the newest generation of asset and liability management models. 